\title{
A Modified Directional Weighted Cascaded-Mask Median Filter for Removal OF RANDOM IMPULSE NOISE
}

\author{
J.K. Mandal ${ }^{1}$ and Aparna Sarkar ${ }^{2}$ \\ ${ }^{1}$ Department of Computer Science \& Engineering, University of Kalyani, \\ Kalyani, Nadia, West Bengal \\ $j \mathrm{~km}$.cse@gmail.com \\ ${ }^{2}$ Department of Computer Science \& Engineering, University of Kalyani, \\ Kalyani, Nadia, West Bengal \\ sarkaraparna09@gmail. com
}

\begin{abstract}
In this paper a Modified Directional Weighted Cascaded-Mask Median (MDWCMM) filter has been proposed, which is based on three different sized cascaded filtering windows. The differences between the current pixel and its neighbors aligned with four main directions. A direction index is used for each edge aligned with a given direction. Then, the minimum of these four direction indexes is used for impulse detection for each and every masking window. Depending on the minimum direction indexes among the three windows one window is selected. The filtering is done on this selected window. Extensive simulations showed that the MDWCMM filter provides good performances of suppressing impulse with low noise level as well as for highly corrupted images from both gray level and colored benchmarked images.
\end{abstract}

\section{KEYWORDS}

Modified Directional Weighted Cascaded-Mask Median filter (MDWCMMF, PSNR, SNR, Median, gray \& color image.

\section{INTRODUCTION}

Impulse noise is often introduced into images during acquisition and transmission [12,13]. Based on the noise values, it can be classified as the easier-to-restore salt-and-pepper noise and the more difficult random-valued impulse noise [9]. Among all kinds of methods for impulse noise, the median filter $[10,11]$ is used widely because of its effective noise suppression capability and high computational efficiency [7]. However, it uniformly replaces the gray-level value of every pixel by the median of its neighbors. Consequently, some desirable details are also removed, especially when the window size is large. In order to improve the median filter, many filters with an impulse detector are proposed. In this paper a modified filter is used for removal of randomvalued impulse noise which performs well in restoration of both low and high valued random impulse noise from both the gray and color images.

In an image, distinct gray levels are to be like their neighbors. So if a pixel value got corrupted, then considering its neighboring gray values we can restore the actual value. This filter

David C. Wyld, et al. (Eds): CCSEA, SEA, CLOUD, DKMP, CS \& IT 05, pp. 81-91, 2012.

(C) CS \& IT-CSCP 2012

DOI : $10.5121 /$ csit.2012.2210 
(MDWCMMF) replaces the value of a pixel by the median of gray levels of neighborhood pixels of that pixel with a certain weight ( 1 or 2 ) and the pixels in the minimum weighted direction.

The minimum weighted direction is one of the four directions (as shown in Figure.1) in which the sum of absolute differences of gray level values between the pivot(central) pixel value and its neighboring pixel values is minimum.

RGB color space is used as the basic color space for the color images. In RGB model colors are represented as a 3-D vector, with red as first element, green as second and blue as third element.

The organization of this paper is as follows. The new impulse detector is formulated in section 2 . Section 3 described the filtering framework. Section 4 provides a number of experimental results to demonstrate the performance of the proposed MDWCMM filter. Conclusions are drawn in section 5 .

\section{IMPULSE DETECTOR}

A noise-free image consists of locally smoothly varying areas separated by edges. Here, we only focused on the edges aligned with four main directions as shown in Figure 1.

Let $S_{k}{ }^{(7)}(k=1$ to 4$)$ denote a set of coordinates aligned with the $\mathrm{k}^{\text {th }}$ direction centered at $(0,0)$, taking $(7 \times 7)$ window, i.e.,

$\mathrm{S}_{1}=\{(-3,-3),(-2,-2),(-1,-1),(0,0),(1,1),(2,2),(3,3)\}$

$\mathrm{S}_{2}=\{(0,-3),(0,-2),(0,-1),(0,0),(0,1),(0,2),(0,3)\}$

$\mathrm{S}_{3}=\{(3,-3),(2,-2),(1,-1),(0,0),(-1,1),(-2,2),(-3,3)\}$

$\mathrm{S}_{4}=\{(-3,0),(-2,0),(-1,0),(0,0),(1,0),(2,0),(3,0)\}$

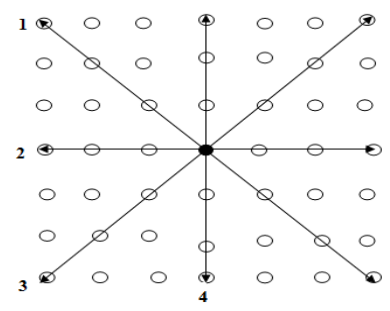

Figure 1: Alignment of edges in four directions

Let $\mathrm{S}_{\mathrm{k}}^{(5)}(\mathrm{k}=1$ to 4$)$ denote a set of coordinates aligned with the $\mathrm{k}^{\text {th }}$ direction centered at $(0,0)$, taking $(5 \times 5)$ window, i.e.,

$S_{1}=\{(-2,-2),(-1,-1),(0,0),(1,1),(2,2)\}$

$\mathrm{S}_{2}=\{(0,-2),(0,-1),(0,0),(0,1),(0,2)\}$

$\mathrm{S}_{3}=\{(2,-2),(1,-1),(0,0),(-1,1),(-2,2)\}$

$\mathrm{S}_{4}=\{(-2,0),(-1,0),(0,0),(1,0),(2,0)\}$

Let $\mathrm{S}_{\mathrm{k}}{ }^{(3)}(\mathrm{k}=1$ to 4$)$ denote a set of coordinates aligned with the $\mathrm{k}^{\text {th }}$ direction centered at $(0,0)$, taking $(3 \times 3)$ window, i.e.,

$\mathrm{S}_{1}=\{(-1,-1),(0,0),(1,1)\}$

$\mathrm{S}_{2}=\{(0,-1),(0,0),(0,1)\}$

$\mathrm{S}_{3}=\{(1,-1),(0,0),(-1,1)\}$

$\mathrm{S}_{4}=\{(-1,0),(0,0),(1,0)\}$ 
Now in a $7 \times 7$ window centered at $(i, j)$, for each direction, define $d_{i, j}{ }^{(p)(k)}$ as the sum of all weighted absolute differences of gray-level values between $y_{i+s, j+t}$ and $y_{i, j}$ with $(s, t) \in S_{k}{ }^{(p)}$ for all $\mathrm{k}$ from 1 to $4, \mathrm{p}=\{7,5,3\}$. Considering that for two pixels whose spatial distance is small, their grey-level values should be close to each other, we will weight the absolute differences between the two closest pixels with a larger value $w_{s, t}$ is very large, it will cause that $d_{i, j}^{(p)(k)}$ is mainly decided by the differences corresponding to $\mathrm{w}_{\mathrm{s}, \mathrm{t}}$. Thus we have eq.4,

$$
\mathrm{d}_{\mathrm{i}, \mathrm{j}}{ }^{(\mathrm{p})(\mathrm{k})}=\sum \mathrm{w}_{\mathrm{s}, \mathrm{t}} *\left|\mathrm{y}_{\mathrm{i}+\mathrm{s}, \mathrm{j}+\mathrm{t}}-\mathrm{y}_{\mathrm{i}, \mathrm{j}}\right|, 1 \leq \mathrm{k} \leq 4,(\mathrm{~s}, \mathrm{t}) \in \mathrm{S}_{\mathrm{k}}^{(\mathrm{p})}
$$

$$
(\mathrm{s}, \mathrm{t})
$$

Where

$$
\begin{aligned}
& \mathrm{w}_{\mathrm{s}, \mathrm{t}}=\left\{\begin{array}{l}
2,(\mathrm{~s}, \mathrm{t}) \in \Omega^{3} \\
1, \text { otherwise }
\end{array}\right. \\
& \Omega^{3}=\{(\mathrm{s}, \mathrm{t}):-1 \leq \mathrm{s}, \mathrm{t} \leq 1\}, \\
& \mathrm{P}=\{3,5,7\} .
\end{aligned}
$$

Here, $d_{i, j}{ }^{(p)(k)}$ are the direction indexes. Each direction index is sensitive to the edge aligned with a given direction. Then, the minimum of these four direction indexes is used for impulse detection, which can be denoted as in eq. 5 .

$\mathrm{r}_{\mathrm{i}, \mathrm{j}}{ }^{(\mathrm{p})}=\min \left\{\mathrm{d}_{\mathrm{i}, \mathrm{j}}{ }^{(\mathrm{p})(\mathrm{k})}: 1 \leq \mathrm{k} \leq 4, \mathrm{p}=\{3,5,7\}\right\}$,

We can find that by employing a threshold $\mathrm{T}_{\mathrm{p}},(\mathrm{p}=\{3,5,7\})$, we can identify the impulse in each window from the noise-free pixels, no matter which are in a flat region, edge or thin line. Then, the pixel $\mathrm{y}_{\mathrm{i}, \mathrm{j}}$ will be noisy if at least one of the following conditions holds

- $\mathrm{r}_{\mathrm{i}, \mathrm{j}}{ }^{(7)}>\mathrm{T}_{7}$

- $\mathrm{r}_{\mathrm{i}, \mathrm{j}}^{(5)}>\mathrm{T}_{5}$

- $\mathrm{r}_{\mathrm{i}, \mathrm{j}}{ }^{(3)}>\mathrm{T}_{3}$

The pixel $\mathrm{y}_{\mathrm{i}, \mathrm{j}}$ will be noise free otherwise.

\section{FILTER}

After impulse detection, we replace the noisy pixels by the calculated median values of the window depending upon the four directions. For this first calculated the standard deviation $\sigma_{\mathrm{i}, \mathrm{j}}{ }^{(\mathrm{p})(\mathrm{k})}$ of grey-level values for all $\mathrm{y}_{\mathrm{i}+\mathrm{s}, \mathrm{j}+\mathrm{t}}$ with $(\mathrm{s}, \mathrm{t}) \in \mathrm{S}_{\mathrm{k}}{ }^{(\mathrm{p})}(\mathrm{k}=1$ to 4$),\{\mathrm{p}=7,5,3\}$, respectively. Let take eq.6 as under

$$
\mathrm{L}_{\mathrm{i}, \mathrm{j}}{ }^{(\mathrm{p})}=\min \left\{\sigma_{\mathrm{i}, \mathrm{j}}{ }^{(\mathrm{p})(\mathrm{k})}: \mathrm{k}=1 \text { to } 4, \mathrm{p}=\{3,5,7\}\right\}
$$

Since the standard deviation describes how tightly all the values are clustered around the mean in the set of pixels, $\mathrm{L}_{\mathrm{i}, \mathrm{j}}{ }^{\mathrm{p})}$ shows the pixels aligned with this direction are the closest to each other. Therefore the center value should also be close to them in order to keep the edges intact.

Three median values are calculated using the eq. 7 as below

$\mathrm{m}_{\mathrm{i}, \mathrm{j}}{ }^{(7)}=\operatorname{median}\left\{\mathrm{w}^{*} \mathrm{y}_{\mathrm{i}+\mathrm{s}, \mathrm{j}+\mathrm{t}}, \mathrm{y}_{\mathrm{i}+\mathrm{p} 1, \mathrm{j}+\mathrm{q}}:(\mathrm{s}, \mathrm{t}),(\mathrm{p} 1, \mathrm{q}) \in \mathrm{S}_{\mathrm{k}}^{(7)}\right\}$

$\mathrm{m}_{\mathrm{i}, \mathrm{j}}{ }^{(5)}=\operatorname{median}\left\{\mathrm{w} * \mathrm{y}_{\mathrm{i}+\mathrm{s}, \mathrm{j}+\mathrm{t}}, \mathrm{y}_{\mathrm{i}+\mathrm{p} 1, \mathrm{j}+\mathrm{q}}:(\mathrm{s}, \mathrm{t}),(\mathrm{p} 1, \mathrm{q}) \in \mathrm{S}_{\mathrm{k}}{ }^{(5)}\right\}$ 
$\mathrm{m}_{\mathrm{i}, \mathrm{j}}^{(3)}=\operatorname{median}\left\{\mathrm{w}^{*} \mathrm{y}_{\mathrm{i}+\mathrm{s}, \mathrm{j}+\mathrm{t}}, \mathrm{y}_{\mathrm{i}+\mathrm{p} 1, \mathrm{j}+\mathrm{q}}:(\mathrm{s}, \mathrm{t}),(\mathrm{p} 1, \mathrm{q}) \in \mathrm{S}_{\mathrm{k}}^{(3)}\right\}$

$\mathrm{w}= \begin{cases}2, & \text { if }-1 \leq(\mathrm{s}, \mathrm{t}) \leq 1 \\ 1, & \text { otherwise }\end{cases}$

$(\mathrm{s}, \mathrm{t})$ pixels are on the minimum direction

And

$-1 \leq(\mathrm{p} 1, \mathrm{q}) \leq 1$; where $(\mathrm{p} 1, \mathrm{q}) \neq(\mathrm{s}, \mathrm{t})$.

Now, we can give the output of the proposed filter as in eq.8.

$u_{i, j}= \begin{cases}u 1, & \text { if } L_{i, j}^{(7)}=L_{i, j}^{(5)} \\ u 1, & \text { if } L_{i, j}(7)=L_{i, j}^{(3)} \\ u 2, & \text { if } L_{i, j}(3)=L_{i, j}(5) \\ (u 1+u 2+u 3) / 3, & \text { otherwise }\end{cases}$

$\mathrm{u} 1=\alpha_{\mathrm{i}, \mathrm{j}} * \mathrm{y}_{\mathrm{i}, \mathrm{j}}+\left(1-\alpha_{\mathrm{i}, \mathrm{j}}\right) * \mathrm{~m}_{\mathrm{i}, \mathrm{j}}^{(7)}$

where,

$\alpha_{i, j}= \begin{cases}0, & \text { if } r_{i, j}{ }^{(7)}>T_{7} \\ 1, & \text { if } r_{i, j}{ }^{(7)} \leq T_{7}\end{cases}$

$\mathrm{u} 2=\alpha_{\mathrm{i}, \mathrm{j}} * \mathrm{y}_{\mathrm{i}, \mathrm{j}}+\left(1-\alpha_{\mathrm{i}, \mathrm{j}}\right) * \mathrm{~m}_{\mathrm{i}, \mathrm{j}}^{(5)}$

where,

$\alpha_{i, j}= \begin{cases}0, & \text { if } r_{i, j}{ }^{(5)}>T_{5} \\ 1, & \text { if } r_{i, j}{ }^{(5)} \leq T_{5}\end{cases}$

$\mathrm{u} 3=\alpha_{\mathrm{i}, \mathrm{j}} * \mathrm{y}_{\mathrm{i}, \mathrm{j}}+\left(1-\alpha_{\mathrm{i}, \mathrm{j}}\right) * \mathrm{~m}_{\mathrm{i}, \mathrm{j}}{ }^{(3)}$

where,

$\alpha_{i, j}= \begin{cases}0, & \text { if } r_{i, j}{ }^{(3)}>T_{3} \\ 1, & \text { if } r_{i, j}{ }^{(3)} \leq T_{3}\end{cases}$

Then substitute

$$
\mathrm{T}=\left\{\begin{array}{c}
\mathrm{y}_{\mathrm{i}, \mathrm{j}}=\mathrm{u}_{\mathrm{i}, \mathrm{j}} \\
\mathrm{T}_{3}, \text { for }(3 \times 3) \text { window } \\
\mathrm{T}_{5}, \text { for }(5 \times 5) \text { window } \\
\mathrm{T}_{7}, \text { for }(7 \times 7) \text { window }
\end{array}\right.
$$

Iteration has been started with the value of $\mathrm{T}=510$ (twice the maximum of gray value). At $\mathrm{T}=510$, the PSNR for the restored image of the $40 \%$ noisy Lenna image(Figure 2.e) was 17.01 $\mathrm{dB}$; but if in the filtering eq.8. was applied recursively and iteratively with decreasing threshold ( $\mathrm{T}=\mathrm{T}^{*} 0.8$ ), the PSNR for the restored images of the $40 \%$ noisy Lenna image has been increased as shown in the table 1 . 
Table 1: PSNR for the restored images of "Lenna" based on changing thresholds, corrupted by $40 \%$ of Random-valued impulse noise

\begin{tabular}{|c|c|}
\hline $\begin{array}{c}\text { Value of threshold, } \\
\mathbf{T}\end{array}$ & $\begin{array}{c}\text { PSNR(dB) for the } \\
\text { restored image of } \\
\mathbf{4 0 \%} \text { noisy Lenna }\end{array}$ \\
\hline $\mathrm{T}=510$ & 17.02 \\
\hline $\mathrm{T}=510 * 0.8$ & 17.54 \\
\hline $\mathrm{T}=(510 * 0.8) * 0.8$ & 17.93 \\
\hline
\end{tabular}

So, for ensuring high accuracy of the detection, we applied our method recursively and iteratively with decreasing threshold $\left(\mathrm{T}=\mathrm{T}^{*} 0.8\right)$, starting with the value $\mathrm{T}=510$, and iterated until $\mathrm{T} \geq$ arithmetic mean of all the pixel values on the minimum direction of the corresponding window.

\section{RESULTS}

Two gray level and two color (RGB) benchmark images have been taken for the experimental purpose. Noises have been injected randomly into the original images to produce noisy images. The enhancement filter generated restored images from these noisy images. Figure 2.a and 2.b are original benchmarked Elaine and Lenna gray images. Figure 2.c and 2.d are original benchmarks, Lenna and Baboon color images. Figure 2.e, Figure 2.g are the noisy images, with $40 \%$ and $60 \%$ noise density, of Lenna where PSNR is $13.93 \mathrm{~dB}$ and $12.57 \mathrm{~dB}$ respectively that of Figure 2.f and Figure 2.h are the filtered image using MDWCMMF where the PSNR is $24.45 \mathrm{~dB}$ and $21.46 \mathrm{~dB}$ respectively. Figure $2 . \mathrm{i}$ shows $40 \%$ corrupted Elaine benchmark image whose PSNR value is $14.13 \mathrm{~dB}$ but when MDWCMM filter has been applied on it, the PSNR obtained is $24.86 \mathrm{~dB}$ (Figure 2.j). Figure 2.m shows 3\% corrupted Baboon (RGB) benchmark image whose PSNR value is 24.07 but when MDWCMM filter has been applied on it, the PSNR obtained is 26.76(Figure 2.n). Figure 2.k shows 30\% noise integrated image where PSNR is 14.49. Application of MDWCMMF on it PSNR increases to 24.01 (Figure. 2.1) from where we may infer that MDWCMM filter may obtain good results in random and high noise removal from gray and color images.

Table 2 shows the comparative PSNR using various filters PWMAD[3], ACWM filter[1,2], AMF[7] including proposed MDWCMM filter applied on Lenna gray image corrupted by various percentages of noise density.

Table 3 and Table 4 shows the comparative PSNR using various filters AVMF[26], IIA[16], MFF[19], ATMED[21], GMED[21], TMAV[21], FSB[25], IFCF[23], MIFCF[23], EIFC[23], SSFCF[23], FIRE[17], PWLFIRE[18], DSFIRE[15], FMF[21], HAF[24], AWFM[22], including proposed MDWCMM filter applied on color Baboon image and color Lenna image corrupted by various percentages of noise density, respectively.

Table 5 shows the effect of applying MDWCMM filter of various images corrupted by $40 \%$ noise. From the table it is also clear that the MDWCMM filter works better for high value of random impulse noise.

Figure 3. shows the comparative performance of the proposed filter applied on gray Lenna corrupted with different levels of impulses among some other existing filters. 
Figure 4. shows the comparative performance of the proposed filter applied on Elaine and Goldhill images corrupted with $40 \%$ impulses among some other existing filters.

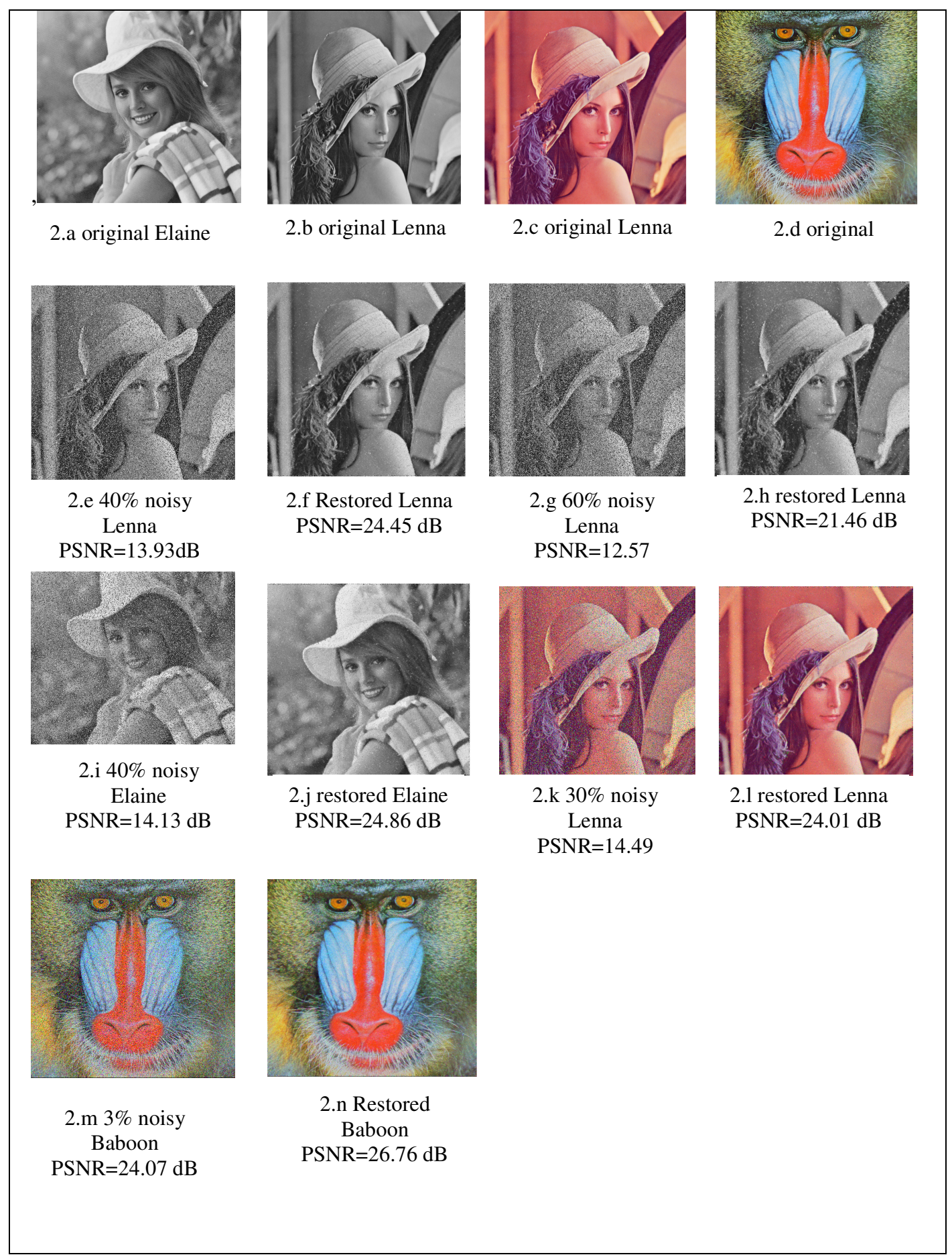

Figue 2.Visual effect of results using MDWCMMF on gray and color images. 
Table 2. Comparative results in PSNR of different algorithms applied to "Lenna" gray image corrupted by various rayes of Random-valued impulse noise

\begin{tabular}{|c|c|c|c|c|c|c|}
\hline \multirow[t]{2}{*}{ Filters } & \multicolumn{6}{|c|}{ PSNR of restored image in $\mathrm{dB}$} \\
\hline & $\begin{array}{l}10 \% \\
\text { Noise }\end{array}$ & $\begin{array}{l}20 \% \\
\text { Noise }\end{array}$ & $\begin{array}{l}30 \% \\
\text { Noise }\end{array}$ & $\begin{array}{l}40 \% \\
\text { Noise }\end{array}$ & $\begin{array}{l}50 \% \\
\text { Noise }\end{array}$ & $\begin{array}{l}60 \% \\
\text { Noise }\end{array}$ \\
\hline PWMAD & 34.86 & 30.58 & 25.94 & 22.41 & 19.42 & 17.08 \\
\hline $\begin{array}{l}\text { ACWM } \\
\text { filter }\end{array}$ & - & 36.07 & 32.59 & 28.79 & 25.19 & 21.19 \\
\hline AMF & 28.06 & 26.79 & 24.03 & 23.17 & 21.99 & - \\
\hline Proposed & 31.14 & 28.16 & 26.08 & 24.45 & 22.96 & 21.46 \\
\hline
\end{tabular}


Figure 3. Comparison among various filters applied on gray Lenna corrupted with different levels of impulses

Table 3. Comparative results in PSNR of different algorithms applied to "Baboon" COLOR image corrupted by various rates of Random-valued impulse noise

\begin{tabular}{|c|c|c|c|c|c|c|c|}
\hline \multirow{2}{*}{ Filters } & \multicolumn{7}{|c|}{ PSNR of restored image in dB } \\
\cline { 2 - 8 } & $\mathbf{3 \%}$ & $\mathbf{5 \%}$ & $\mathbf{1 0 \%}$ & $\mathbf{1 5 \%}$ & $\mathbf{2 0 \%}$ & $\mathbf{2 5 \%}$ & $\mathbf{3 0 \%}$ \\
\hline AVMF & 27.4 & 26.0 & 25.1 & 24.3 & 22.9 & 21.5 & 20.3 \\
\hline MFF & 25.0 & 24.9 & 24.4 & 23.6 & 22.5 & 21.2 & 19.8 \\
\hline ATMED & 24.4 & 24.3 & 24.0 & 23.7 & 23.5 & 23.2 & 22.2 \\
\hline GMED & 24.7 & 24.6 & 24.2 & 23.7 & 23.0 & 22.0 & 20.7 \\
\hline TMAV & 24.8 & 24.7 & 24.4 & 23.8 & 23.0 & 21.9 & 20.7 \\
\hline FSB & 24.6 & 24.5 & 24.1 & 23.6 & 22.9 & 21.9 & 20.9 \\
\hline
\end{tabular}




\begin{tabular}{|c|c|c|c|c|c|c|c|}
\hline IFCF & 24.8 & 24.7 & 24.1 & 23.5 & 22.8 & 22.0 & 20.7 \\
\hline MIFCF & 25.2 & 25.0 & 24.2 & 23.2 & 22.2 & 20.9 & 19.6 \\
\hline EIFCF & 24.9 & 24.7 & 24.0 & 23.4 & 22.7 & 21.7 & 20.7 \\
\hline SSFCF & 24.8 & 24.6 & 24.0 & 23.1 & 21.9 & 20.5 & 19.0 \\
\hline FIRE & 28.3 & 27.5 & 25.6 & 23.5 & 21.6 & 19.8 & 18.2 \\
\hline PWLFIRE & 37.7 & 34.8 & 29.3 & 25.3 & 22.3 & 19.8 & 17.9 \\
\hline DSFIRE & 33.2 & 32.4 & 30.7 & 29.0 & 27.6 & 25.9 & 24.2 \\
\hline FMF & 32.0 & 30.3 & 27.7 & 25.8 & 24.2 & 22.6 & 21.0 \\
\hline HAF & 24.6 & 24.5 & 24.4 & 24.3 & 24.2 & 24.1 & 23.9 \\
\hline AWFM & 25.0 & 24.8 & 24.4 & 24.1 & 23.8 & 23.5 & 23.2 \\
\hline Proposed & 26.76 & 26.18 & 24.94 & 23.97 & 23.13 & 22.41 & 21.77 \\
\hline
\end{tabular}

Table 4. Comparative results in PSNR of different algorithms applied to "Lenna" COLOR image corrupted by various rayes of Random-valued impulse noise

\begin{tabular}{|c|c|c|c|c|c|c|c|}
\hline \multirow{2}{*}{ Filters } & \multicolumn{7}{|c|}{ PSNR of restored image in dB } \\
\cline { 2 - 8 } & $\mathbf{3 \%}$ & $\mathbf{5 \%}$ & $\mathbf{1 0 \%}$ & $\mathbf{1 5 \%}$ & $\mathbf{2 0 \%}$ & $\mathbf{2 5 \%}$ & $\mathbf{3 0 \%}$ \\
\hline AVMF & 37.3 & 36.2 & 33.9 & 32.1 & 30.3 & 27.8 & 25.6 \\
\hline IIA & 34.3 & 33.5 & 30.6 & 27.3 & 24.9 & 23.5 & 22.0 \\
\hline MFF & 28.8 & 28.5 & 27.8 & 27.0 & 26.1 & 25.0 & 23.8 \\
\hline ATMED & 30.3 & 29.9 & 28.8 & 27.8 & 26.6 & 25.3 & 24.1 \\
\hline GMED & 31.2 & 31.0 & 30.1 & 29.3 & 28.2 & 26.7 & 25.3 \\
\hline TMAV & 31.0 & 30.7 & 29.8 & 28.7 & 27.4 & 25.9 & 24.5 \\
\hline FSB & 30.7 & 30.6 & 29.8 & 29.1 & 28.1 & 26.6 & 25.3 \\
\hline IFCF & 30.7 & 30.4 & 29.4 & 28.7 & 27.8 & 26.6 & 25.6 \\
\hline MIFCF & 30.9 & 30.6 & 29.4 & 28.5 & 27.4 & 26.1 & 25.0 \\
\hline EIFCF & 30.5 & 30.3 & 29.4 & 28.7 & 27.8 & 26.6 & 25.6 \\
\hline SSFCF & 30.3 & 30.1 & 29.3 & 28.4 & 27.1 & 25.6 & 24.2 \\
\hline FIRE & 34.3 & 32.6 & 29.7 & 27.6 & 25.7 & 23.9 & 22.4 \\
\hline PWLFIRE & 31.1 & 28.8 & 25.5 & 23.4 & 21.7 & 20.4 & 19.1 \\
\hline DSFIRE & 30.5 & 28.6 & 25.8 & 24.1 & 22.7 & 21.6 & 20.6 \\
\hline
\end{tabular}




\begin{tabular}{|c|c|c|c|c|c|c|c|}
\hline FMF & 36.4 & 24.8 & 31.9 & 30.2 & 28.5 & 26.4 & 24.9 \\
\hline HAF & 29.6 & 29.2 & 27.8 & 26.6 & 25.2 & 24.0 & 22.7 \\
\hline AWFM & 31.3 & 30.8 & 29.3 & 28.0 & 26.2 & 24.7 & 23.1 \\
\hline Proposed & 34.98 & 33.38 & 30.70 & 28.98 & 27.66 & 26.56 & 25.62 \\
\hline
\end{tabular}

Table 5. comparative results in PSNR of different algorithms applied to various kinds of gray images corrupted with $40 \%$ of random-valued impulse noise

\begin{tabular}{|c|c|c|c|c|}
\hline \multirow{2}{*}{ Filters } & \multicolumn{4}{|c|}{ PSNR of restored image in dB } \\
\cline { 2 - 5 } & Elaine & Goldhill & Pepper & Airplane \\
\hline PWMAD & 24.66 & 24.16 & 24.63 & 24.37 \\
\hline Trilateral & 19.38 & 19.14 & 19.53 & 19.54 \\
\hline TSM & 20.26 & 20.02 & 20.14 & 19.37 \\
\hline Proposed & 24.86 & 24.88 & 23.96 & 23.20 \\
\hline
\end{tabular}

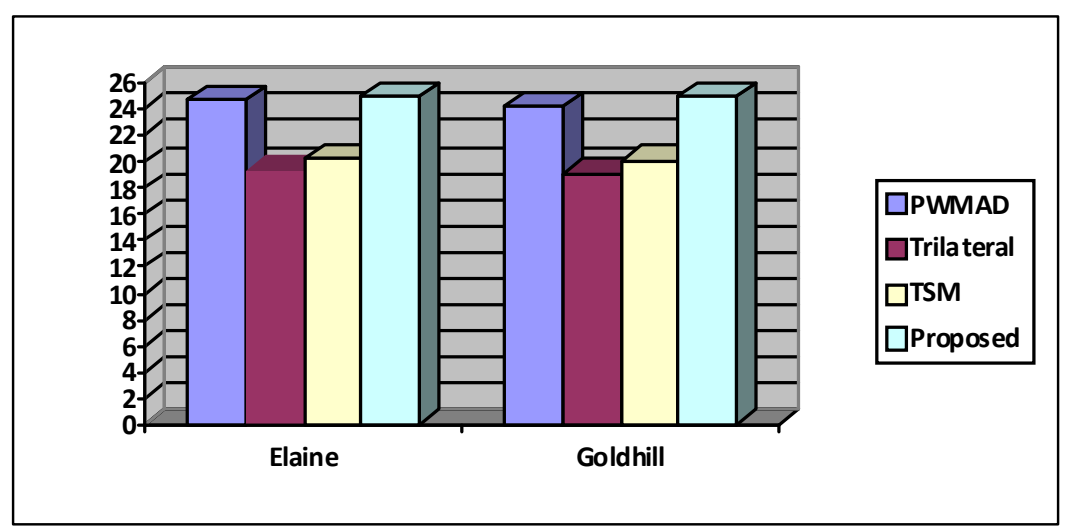

Figure 4. Comparison among various filters applied on various images corrupted with $40 \%$ noise

\section{CONCLUSIONS}

In this paper, we proposed a new directional weighted cascaded mask median-based filter, for removing random-valued impulse noise. It makes full use of the characteristics of impulse and edges to detect and restore noise. Since PSNR represents the ratio between the maximum possible power of a signal and the power of corrupting noise, the higher value of PSNR for filtered image than the PSNR value for the corrupted image gives better result .Simulation results showed that this filter performs much better than many existing median-based filters in both subjective and objective (PSNR) evaluations. 


\section{ACKNOWLEDGMENT}

The authors expressed deep sense of gratitude to the IIPC Project of AICTE, Government of India and to the department of CSE, University of Kalyani where the computational work has been carried out.

\section{REFERENCES}

[1] Yiqiu Dong and Shufang Xu , "A New Directional Weighted Median Filter for Removal of RandomValued Impulse Noise",IEEE SIGNAL PROCESSING LETTERS, VOL. 14, NO. 3, MARCH 2007

[2] T. Chen and H. R. Wu, "Adaptive impulse detection using center-weighted median filters," IEEE Signal Process. Lett., vol. 8, no. 1, pp. 1-3, Jan. 2001.

[3] V. Crnojevi'c, V. `Senk and ` Z. Trpovski, "Advanced impulse detection based on pixel-wise MAD," IEEE Signal Processing Letters, vol. 11, pp. 589-592, 2004.

[4] Waqas Nawaz, Arfan Jaffar, and Ayyaz Hussain," Fast Directional Weighted Median Filter for Removal of Random-Valued Impulse Noise”, 978-1-4244-8003-6/10/\$26.00 @2010 IEEE.

[5] X. Li and M. Orchard, "True edge-preserving filtering for impulse noise removal," in presented at the 34th Asilomar Conf. Signals, Syst. Comput.,Pacific Grove CA, Oct. 2000.

[6] Sheng-Fu Liang, Shih-Mao Lu, Jyh-Yeong Chang, Chin-Teng (CT) Lin , "A Novel Two-Stage Impulse Noise Removal Technique Based on Neural Networks and Fuzzy Decision" IEEE TRANSACTIONS ON FUZZY SYSTEMS, VOL. 16, NO. 4, AUGUST 2008863

[7] Wang H, Haddad R A, Adaptive median filters: New algorithms and results, IEEE Transactions on Image Processing, vol. 4, 1995, pp 499-502.

[8] Tao Chen, Kai-Kuang Ma and Li-Hui Chen (1999), 'Tri-State Median Filter for Image Denoising', IEEE Trans. on Image Processing, Vol. 8, No.8, pp.1-3, 1999.

[9] T. Chen and H. R. Wu, "Space variant median filters for the restoration of impulse noise corrupted images”, IEEE Trans. Circuits Syst. II, vol. 48, no. 8, pp. 784-789, Aug. 2001.

[10] W. K. Pratt, “Median filtering,” Image Process. Inst., Univ. Southern California, Los Angeles, Sep. 1975, Tech. Rep..

[11] S. Zhang and M. A. Karim, "A new impulse detector for switching median filters," IEEE Signal Process. Lett., vol. 9, no. 11, pp. 360-363, Nov. 2002.

[12] Pankaj Kr. Sa, Ratnakar Dash, Banshidhar Majhi,"Second order difference based detection and directional weighted median filter for removal of random valued impulse noise", 4th IEEE International Conference on Industrial \& Information Science, 28-31 Dec. 2009.

[13] E. Abreu, M. Lightstone, S. K. Mitra, and K. Arakawa, "Anew efficient approach for the removal of impulse noise from highly corrupted images", IEEE Trans. Image Process., vol. 5, no. 6, pp. 10121025, Jun. 1996.

[14] V. Crnojevic, V. Senk, and Z. Trpovski, "Advanced Impulse Detector Based on Pixel-Wise MAD" IEEE Signal Processing Letters, vol. 11, no. 7, pp.589-592, July 2004.

[15] S. Schulte, V. D. Witte, M Nachtegael, D.V. D. Weken, and E.E. Kerre,"Fuzzy two-step filter for impuldse noise reduction from color images", IEEE transactions on image processing, vol. 15, no. 11, Nov. 2006.

[16] S. M. Guo, C. S. Lee, and C. Y. Hsu, "An intelligent image agent based on soft-computing techniques for color image processing”, Expert Syst. Appl., vol. 28, pp. 483-494, Apr 2005.

[17] F. Russo and G. Ramponi,"A fuzzy filter for image corrupted by impulse noise", IEEE Signal Processing Letters, vol. 3, no. 6, pp.168-170, Jun 1996.

[18] F. Russo, "Fire operators in image procesing", Fuzzy Sets and Syst., vol. 103, pp. 265-275,Apr 1999.

[19] F. Russo and G. Ramponi,"A noise smoother using cascaded FIRE filters", in proc. IEEE 4th Int. Conf. Fuzzy Systems, vol. 1, pp.351-358, Mar. 1995.

[20] K. Arakawa, "Median filter based on fuzzy rules and its application to image restoration", Fuzzy Sets and Syst., vol. 77, pp. 3-13, Jun 1996.

[21] H.K. Kwan, "Fuzzy filters for noise reduction in image", in Fuzzy filters for image processing, M. Nachtegael, D. Van der Weken, D. Van De Ville, and E. E. Eds, 1st Ed., Heidelberg, Germany: Physica Verlag, 2003, vol. 122, pp. 25-53.

[22] C. S. Lee, Y. H. Kuo, and P.T.Yu, "Weighted fuzzy mean filters for image processing”, Fuzzy Sets and Syst., vol. 89, pp. 157-180, Jun 1997.

[23] F. Ferbiz, M. B. Menhaj, and S.A. Motamedi, "Edge preserving image filtering based on fuzzy logic", in proc. 6th EUFIT conf., 1998, pp. 1417-1421.

[24] H.G. Wang and H.C.Chiu, "An adaptive fuzzy filter for restoring highly corrupted images by histogram estimation", in Proc. Nat. Sci. Council Part A, 1999, vol. 23, pp. 630-643.

[25] I. Kalaykov and G. Tolt, M M. Nachtegael, D. Van der Weken, D. Van De Ville, and E. E. Eds,"Realtime image noise cancellation based on fuzzy similarity", 1st Ed., Heidelberg, Germany: Physica Verlag, 2003, vol. 122, pp. 54-71. 
[26] R. Lukac, “Adaptive vector median filter”, Pattern Recognit. Lett., vol. 24,pp. 1889-1899, Aug. 2003.

\section{Authors}

J. K. Mandal:M. Tech. ( Computer Science, University of Calcutta ), Ph.D. ( Engg., Jadavpur University ) in the field of Data Compression and Error Correction Techniques, Professor in the dept. of Computer Science and Engineering, University of Kaly ani, India. He is life member of Computer Society of India since 1992 and life member of Cryptography Research Society of India. Currently, he is working in the field of Network Security, Steganography, Remote sensing \& GIS Application, and Image Processing. He has 25 years of teaching and research experiences. Eight Scholars awarded Ph.D. one submitted and 8 are pursuing. Total no. of publications is 228 .

Aparna Sarkar:Ms. Aparna Sarkar is pursuing M.Tech in Computer Science and Engineering from University of Kalyani in the department of Computer Science and Engineering. She obtained her B.Sc $(\mathrm{H})$ degree in Computer Science and MCA degree from University of Kalyani in 2007 and 2010 respectively. She has 3 publications in her credit.
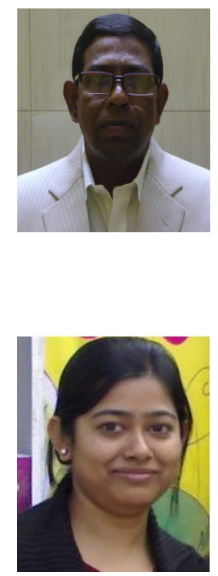